\title{
Pengembangan Konsep "Indo-Pasifik": Sebuah Konstruksi Geopolitik Indonesia di Kawasan Melalui ASEAN
}

\author{
Pradipta Nindyan Saputra ${ }^{1}$, Arfin Sudirman ${ }^{2}$ \\ pradiptanindyan@gmail.com, arfin.sudirman@unpad.ac.id \\ 1 Mahasiswa Program Pascasarjana. Program Studi Ilmu Politik Peminatan Hubungan Internasional. Universitas \\ Padjadjaran Bandung \\ 2 Dosen Pascasarjana. Program Studi Ilmu Politik Peminatan Hubungan Internasional. Universitas Padjadjaran \\ Bandung. \\ DOI http://dx.doi.org/10.22219/sospol.v6i2.7254
}

\begin{abstract}
The concept of geopolitics appears to bridge the relationship between geographical factors in contemporary politics. Through its focus on geographical factors, geopolitics has a very materialistic and objective foundation. Based on a critical examination of the implementation of the concept, it becomes clear that the geopolitical framework depends on social construction. Through qualitative methods, this article tries to explain that the concept of "Indo-Pacific" which is of international concern at the moment, is inseparable from a geopolitical construction carried out by the countries concerned. The significance of this new regional concept has been contested by some countries such as the United States, China, India, Australia, and Japan. Seeing its position at the Indo-Pacific geopolitical junction, Indonesia felt the need to make a geopolitical construction effort to encourage the creation of a better regional ecosystem, not as an arena for conflicting interests, as happened in the AsiaPacific region. As part of the geopolitical construction effort and changing perceptions of all countries in the region, Indonesia through the ASEAN framework continues to promote the Indo-Pacific region which is open, free, and inclusive in various international forums.
\end{abstract}

\begin{abstract}
Abstrak
Konsep geopolitik muncul untuk menjembatani hubungan antara faktor geografi dalam politik kontemporer. Melalui fokusnya pada faktor geografi, geopolitik memiliki landasan yang sangat materialistis dan objektif. Berdasar pemeriksaan kritis terhadap implementasi konsep tersebut, menjadi jelas bahwa kerangka geopolitik bergantung pada konstruksi sosial. Melalui metode kualitatif, artikel ini mencoba menjelaskan bahwa konsep "Indo-Pasifik" yang menjadi perhatian internasional saat ini, tidak lepas dari sebuah konstruksi geopolitik yang dilakukan oleh negara-negara yang berkepentingan. Arti penting dari konsep kawasan baru ini ini telah diperebutkan oleh sejumlah negara seperti Amerika Serikat, Tiongkok, India, Australia, dan Jepang. Melihat posisinya yang berada di persimpangan geopolitik Indo-Pasifik, Indonesia merasa perlu melakukan sebuah upaya konstruksi geopolitik untuk medorong terciptanya ekosistem kawasan yang lebih baik, bukan sebagai arena untuk beradu kepentingan, sebagaimana yang terjadi di kawasan Asia-Pasifik. Sebagai bagian dari upaya konstruksi geopolitik dan mengubah persepsi semua negara di kawasan, Indonesia melalui kerangka ASEAN terus mempromosikan kawasan Indo-Pasifik yang terbuka, bebas, dan inklusif dalam berbagai forum internasional.
\end{abstract}

\author{
Keywords: \\ ASEAN, \\ Constructivism, \\ Geopolitics, Indo-Pacific
}

\section{Article History:}

Received January 9, 2020

Revised June 30, 2020

Accepted August 31, 2020

Publshed October 17, 2020

\section{Corresponding Author Pradipta Nindyan Saputra. Perumahan Panorama Jatinangor B.26, Desa Cinanjung, Kecamatan Tanjungsari, Kabupaten Sumedang, Jawa Barat 45362}

\section{Pendahuluan}

Dalam 10 tahun ke belakang, istilah "Indo-Pasifik" mulai jamak digunakan dalam studi geopolitik, menggantikan istilah yang telah dikenal sebelumnya yakni "Asia-Pasifik". Sering didefinisikan sebagai sebuah konsep strategis terintegrasi yang mampu menangkap pergeseran 
power dan pengaruh (influence) dari barat ke timur, konsep ini telah mendominasi berbagai perdebatan strategis dan juga diskusi. Meskipun istilah ini telah menjadi begitu populer, namun, logika yang mendasari konstruksi geopolitik konsep ini masihlah diperdebatkan dengan tajam. Akibatnya, konsep "Indo-Pasifik" belum mendapatkan penerimaan secara penuh di kalangan analis dan pembuat kebijakan regional, yang masih belum yakin untuk merangkul ide tersebut secara utuh. Namun begitu, tidak dapat disangkal bahwa konsep Indo-Pasifik muncul sebagai ruang strategis yang signifikan dan juga sebagai teater kekuatan-kekuatan besar bersaing secara geopolitik (Ayres, 2019; Chen, 2018; Gurpreet Singh Khurana, 2017; Natalegawa, 2013).

Secara geografis wilayah Indo-Pasifik merujuk pada kawasan yang membentang dari bagian timur Samudera Hindia ke Samudra Pasifik bagian barat dan terhubung dengan Selat Malaka. Indo-Pasifik telah menjadi pusat kegiatan geopolitik maritim, keamanan, perdagangan, dan lingkungan (Passarelli, 2014). Kawasan Indo-Pasifik juga berdiri di persimpangan perdagangan internasional. Nilai strategis sebagai pusat geopolitik ditekankan oleh kehadiran negara-negara kuat seperti Amerika Serikat, Tiongkok, India, Australia, Jepang, dan juga negaranegara ASEAN.

Namun, jauh melampaui deskripsi geografis, konsep Indo-Pasifik pada dasarnya merupakan arsiteksur baru geopolitik kawasan. Para pendukung konsep Indo-Pasifik mengasumsikan bahwa pertumbuhan hubungan ekonomi (De, 2019), kebutuhan akan kerja sama dan koordinasi politik dan keamanan yang lebih besar membutuhkan suatu perluasan konsep kawasan. Indonesia dan India menurut beberapa kalangan dianggap penting dalam proses regionalisasi dan regionalisme ini dan merupakan pengadopsi awal dari ide Indo-Pasifik (Khurana, 2017). Inisiatif Indonesia terhadap pengembangan konsep Indo-Pasifik salah satunya didasarkan atas serangkaian kekhawatiran keamanan dan ekonomi yang di dominasi oleh persaingan antara Beijing dan Washington dalam kerangka Asia-Pasifik (Natalegawa, 2013). Keinginan untuk meningkatkan pertumbuhan ekonomi dan mencegah dominasi ekonomi dan politik Tiongkok di wilayah ini merupakan pendorong penting atas konstruksi geopolitik yang coba dimainkan oleh Indonesia di kawasan. Faktor-faktor ini menempatkan pembatasan signifikan pada integrasi regional Indo-Pasifik yang coba dipromosikan oleh Indonesia, berbeda dengan pemahaman konsep Indo-Pasifik dalam pemahaman negara besar lain seperti Amerika Serikat (Ayres, 2019).

Berbeda dengan penelitian sebelumnya yang memposisikan Indo-Pasifik sebagai sesuatu yang given (Agastia \& Perwita, 2016; Damayanti, 2019; Tertia \& Perwita, 2018), tulisan ini lebih melihat konsepsi Indo-Pasifik merupakan sebuah konstruksi sehingga kemudian menarik untuk melihat bagaimana bentuk konstruksi geopolitik Indonesia di dalam kawasan baru ini, dengan memeriksa secara holistik strategi yang diambil oleh Indonesia dalam mempromosikan konsep Indo-Pasifik ala mereka, kemudian mengartikan tren yang mempengaruhi arsitektur regional atas konstruksi tersebut. Ini memberikan perspektif tentang kondisi geopolitik Indo-Pasifik, mengevaluasi implikasi yang muncul akibat konstruksi yang dilakukan oleh Indonesia menggunakan kerangka acuan Konstruktivisme yang menekankan konstruksi sosial yang berdasar pada aspek nilai dan norma. Ini menjadi penting karena Indonesia ingin berperan lebih aktif dalam arsitektur baru ini dengan menempatkan posisinya sebagai salah satu pemain utama bersama dengan ASEAN di kawasan. 


\section{Tinjauan Pustaka}

Dalam pandangan Konstruktivisme, realitas sosial bukanlah sesuatu yang given, namun merupakan suatu hasil konstruksi para aktor hubungan Internasional (Wendt, 1992). Konstruktivisme adalah sebuah pendekatan yang menguji konteks dan lingkungan material dan sosial di mana seorang pelaku tinggal dan mencoba untuk memahami bagaimana konteks ini mempengaruhi pemahaman kepentingan para aktor yang bersangkutan (Hadiwinata, 2017). Dengan demikian, di bawah Konstruktivisme, konsepsi norma adalah "pemahaman kolektif yang membuat klaim perilaku pada aktor", yang merupakan identitas dan kepentingan aktor. Hopf berpendapat bahwa pandangan konstruktivis tentang perilaku yang bermakna hanya mungkin dalam konteks sosial intersubjektif di mana aktor mengembangkan hubungan dan pemahaman orang lain melalui norma-norma ini (Hopf, 2012). Dalam tulisan ini, definisi Konstruktivisme ini akan digunakan dalam kaitannya dengan geopolitik, yaitu, untuk menunjukkan bahwa konsep geopolitik dipengaruhi oleh konteks di mana mereka hidup.

Dalam definisi yang paling sederhana, geopolitik berkaitan dengan aspek politik dari konsep geografis seperti batas teritorial negara dan sumber daya. Bahkan, istilah itu sendiri secara semantis mengungkapkan hubungan khusus antara lingkungan terestrial dan aktivitas politik yang terjadi dalam lingkungan itu. Akibatnya, geopolitik memberikan cara tertentu untuk memahami dunia dengan menjelaskan bagaimana lokasi teritorial dan sumber daya alamnya mempengaruhi pembentukan politik nasional dan internasional. Namun, wacana geopolitik sendiri lebih dari sekadar dampak geografi dengan terhadap negara. Kenyataannya, makna yang tepat dari geopolitik dan relevansinya terhadap situasi tertentu kadang-kadang bisa kurang jelas, karena istilah itu digunakan akan berbeda tergantung pada konteks yang menyertainya (Bachmann \& Sidaway, 2016). Yang menarik, sebagaimana dikemukanan oleh Geoffrey Parker bahwa ketiadaan presisi ini dapat menjadi salah satu atraksi geopolitik tertentu. Artinya, setiap negara berpotensi untuk melakukan konstruksi geopolitik bergantung pada kepentingan, nilai, serta norma yang diyakininya. Selain itu, Parker berpendapat bahwa selama abad ke-20, geopolitik dipahami sebagai mobilisasi pengetahuan geografis untuk tujuan negara, yang tunduk pada wacana geopolitik untuk memanipulasi negara-negara dalam rangka membenarkan pengejaran mereka terhadap kepentingan atau kebijakan tertentu (Parker, 1998).

Dalam perkembangannya, geopolitik kontemporer mengarah kepada pendekatan geopolitik kritis, yang secara eksplisit memasukkan pemahaman sosial para aktor dalam wacana. Titik awal untuk geopolitik kritis adalah bahwa geopolitik konvensional mengabaikan asumsi yang mendukung posisi para pemikir geopolitik itu sendiri. Untuk memperbaiki kesenjangan ini, geopolitik kritis berpendapat bahwa karena sudut pandang yang terpisah dan obyektif tidak mungkin, maka harus diakui secara eksplisit bahwa geopolitik itu sendiri berada dalam asumsi konseptual dan metodologis dunia (Woon, 2018). Dengan demikian, geopolitik kritis berpendapat bahwa geopolitik tidak bisa lagi sekadar menjadi studi kenegaraan dan manajemen urusan internasional, tetapi sebaliknya harus menjadi wacana yang berkaitan dengan hubungan antara pengetahuan, power, dan hubungan sosial dan politik dalam interaksi geografi, pengetahuan, dan institusi politik dan sosial (Vihma, 2018). Tuathail berpendapat bahwa premis dasar geopolitik kritis adalah anggapan bahwa geografi adalah wacana sosial dan historis yang selalu terikat erat dengan pertanyaan-pertanyaan politik dan ideologi, sehingga 
pada kenyataannya, konsep geografi adalah bentuk dari kekuasaan- pengetahuan itu sendiri (Tuathail \& Agnew, 1992).

\section{Metode}

Metode penelitian yang digunakan dalam penelitian ini adalah kualitatif berbasis dokumen (document-based research) (Bakry, 2016) atau dalam istilah lain adalah penelitian kualitatif berbasis studi pustaka (Creswell, 2016). Penelitian kualitatif adalah metode penelitian yang pada umumnya memanfaatkan sumber data non-numerik. Penelitian kualitatif yang digunakan dalam penelitian ini adalah penelitian kualitatif deduktif yang melihat hubungan antara konsep dan data penelitian. Untuk menjelaskan suatu fenomena tertentu, penelitian deduktif disusun berdasarkan kerangka analisis yang spesifik.

Penelitian ini mencoba menggabungkan analisis data primer dan data sekunder. Data primer didapat dari dokumen-dokumen resmi (official documents) yang dirilis oleh pemerintah (Bakry, 2016), sebagai contoh dokumen Pernyataan Pers Tabunan Menteri Luar Negeri Republik Indonesia Y.M. Retno L. P. Marsudi dan juga Undang-Undang Dasar 1945. Data primer selanjutnya didapatkan dari laman resmi instansi pemerintah yang memiliki pemahaman ataupun mengeluarkan pernyataan terkait dengan posisi geopolitik Indonesia dan konsep "Indo-Pasifik" yang dikembangkan oleh Indonesia, seperti: laman resmi Kementerian Luar Negeri Republik Indonesia dan juga laman Sekretariat Kabinet Republik Indonesia. Sedangkan data sekunder diperoleh dari kajian-kajian literatur yang telah ada dan memiliki kontribusi terhadap penelitian ini, seperti: buku, jurnal, artikel, dokumen, surat kabar yang telah melalui triangulasi data sehingga dapat digunakan untuk mendukung keperluan penelitian (Azwar, 2010).

\section{Hasil dan Pembahasan}

Pasca lengsernya Presiden Amerika Serikat (AS) Barack Obama, ada tren perubahan arah kebijakan luar negeri AS di bawah kepemimpinan Presiden Donald Trump dari "AsiaPasifik" ke "Indo-Pasifik". Kebijakan Trump tersebut secara tersirat adalah ekspansi dan revisi "Asia-Pacific rebalancing strategy" di masa pemerintahan sebelumnya. Dari perspektif geopolitik, pergeseran kebijakan luar negeri AS dari "Asia-Pasifik" di masa Obama (Glosserman, 2016), menjadi "Indo-Pasifik" di masa Trump tersebut disebabkan karena AS merasakan adanya tantangan yang terus tumbuh dari Tiongkok dan bertekad untuk mempertahankan supremasi global dengan terus meningkatkan kehadiran militernya di Indo-Pasifik dan meningkatkan kerjasama strategis dengan mitra segi empatnya: Jepang, Australia dan India (Saeed, 2017). Masuknya India ke dalam perhatian AS tidak dapat dilepaskan dari faktor di mana beberapa tahun belakangan ini, India telah menjadi pemimpin di antara negara-negara berkembang (Chen, 2018).

Indonesia menyadari konvergensi strategis akibat pergesaran pusat perhatian ekonomi dan geopolitik global tersebut. Secara strategis, Indonesia terletak di titik tumpu geopolitik global serta koridor perdagangan dan energi utama di kawasan ini. Indonesia memiliki ruang geostrategis yang sangat penting karena empat bagian wilayah maritim strategis, yakni: Selat Malaka, Selat Lombok, Selat Sunda, dan Selat Ombai, berada di bawah yurisdiksi maritimnya. Kontrol atas empat wilayah maritim ini memungkinkan Indonesia berperan sebagai tonggak strategi Indo-Pasifik karena negara kepulauan seperti Indonesia tidak hanya bisa memberi akses 
negara-negara dari Samudera Hindia ke Samudera Pasifik, tetapi juga menawarkan prospek untuk bersama-sama memantau jalur pelayaran di kawasan itu, terutama sejak agresifitas Angkatan Laut Tiongkok meningkat secara dramatis selama dekade terakhir. Oleh karenanya, Indonesia memandang penting pengembangan konsep Indo-Pasifik melalui ASEAN untuk terus mempertahankan sentralitasnya dan menjadikan kawasan Indo-Pasifik sebagai kawasan yang kooperatif, inklusif, terbuka, transparan, dan menghormati hukum internasional, karena bagi Indonesia kondisi tersebut dapat mempengaruhi peran sentral dan relevansi ASEAN sebagai poros Indo-Pasifik.

Dalam pandangan pendukung konsep Indo-Pasifik, pertumbuhan hubungan ekonomi, kebutuhan akan kerja sama politik dan keamanan yang lebih besar, serta pembangunan ketertiban mengarah pada integrasi kawasan. Chacko dan Willis menunjukkan bahwa India dan Indonesia dianggap penting dalam proses-proses regionalisasi dan regionalisme dari Indo-Pasifik karena India dan Indonesia mewakili poros Samudera Hindia dan Samudera Pasifik (Chacko \& Willis, 2018). Lebih lanjut, dikatakan bahwa serangkaian kekhawatiran keamanan dan ekonomi yang saling terkait mendorong India dan Indonesia mengadopsi konsep Indo-Pasifik. ASEAN sebagai organisasi yang menaungi negara-negara di Asia Tenggara dikatakan menyambut sejumlah kekuatan besar di Indo-Pasifik untuk "bersaing secara konstruktif” (constructively competing) untuk menyediakan perdagangan, investasi, teknologi dan hubungan militer bagi negara anggota ASEAN, dengan Indonesia dan India sebagai mitra utama (Limaye, 2014), namun tetap persaingan tersebut harus berlandaskan pada prinsip saling menghormati kedaulatan negara lain.

Sejauh ini dalam literatur yang sudah ada cenderung untuk menempatkan posisi ASEAN di dalam arsitektur "Indo-Pasifik" tidak lebih dari objek kepanjangan tangan negara besar seperti AS dan Jepang untuk menangkal pengaruh Tiongkok di kawasan (Wagle, 2018). Padahal, Indonesia memandang ASEAN dapat memainkan peranan utama di dalam konsep kawasan baru tersebut. Pandangan Indonesia tersebut dilandasi oleh suatu fakta bahwa, di kawasan Asia-Pasifik, meskipun belum bisa dikatakan berhasil menyelesaikan konflik, namun ASEAN adalah satu-satunya organisasi yang dapat dikatakan berhasil mengelola potensi konflik di kawasan (Darmawan \& Kuncoro, 2019). ASEAN telah membuktikan bahwa, berbagai prinsip, nilai, dan norma yang dipegang oleh ASEAN telah menjadikan ASEAN sebagai organisasi yang terus konsisten dari sejak awal dibentuk untuk memperjuangkan nilai-nilai kerja sama agar menghilangkan potensi konflik. Oleh karenanya, Indonesia terus proaktif dalam mengembangkan konsep Indo-Pasifik ini di kawasan dalam kerangka ASEAN untuk kembali menempatkan Indonesia dan ASEAN pada posisi sentral, sehingga dalam konsep Indo-Pasifik nanti, tidak hanya diwarnai oleh tarik-menarik kepentingan negara-negara besar saja.

Penjelasan menarik tentang hubungan antara Konstruktivisme dan geopolitik (konstruksi geopolitik) datang dari tulisan Mateusz Ambrozek (2017) bahwa geopolitik tidak bekerja dalam ruang hampa, artinya geopolitik dapat dibentuk dengan mengurangi maupun menambah suatu faktor yang paling relevan dengan kepentingan suatu negara. Ini berarti fenomena geopolitik yang ada di suatu kawasan merupakan hasil konstruksi dari negara-negara di kawasan tersebut. Lebih terperinci, dalam tulisan yang berjudul "The North Natuna Sea Renamed as Geopolitics of Indonesia in Natuna”, Yugolastarob Komeini dkk menunjukkan bagaimana Indonesia melakukan konstruksi geopolitik di kawasan Laut Tiongkok Selatan melalui strategi merubah nama laut di utara kepulauan Natuna untuk menangkal klaim Tiongkok sekitar 
kawasan tersebut (Situmeang \& Fadra., 2018). Strategi ini yang kembali coba dimainkan Indonesia di dalam upaya konstruksi geopolitik di kawawsan yakni dengan membangun dan mengembangkan suatu konsepsi Indo-Pasifik yang sesuai dengan kepentingan nasionalnya, serta menganut nilai dan norma yang selama ini telah diimplementasikan oleh ASEAN di kawasan.

Konsep Indo-Pasifik sendiri merupakan salah satu isu yang menjadi perhatian banyak kalangan akademisi dalam dekade terakhir, terutama sejak istilah ini muncul pertama kali dalam tulisan Gurpreet S. Khurana yang berjudul "Security of Sea Lines: Prospects for India-Japan Cooperation" (Khurana, 2007). Bagi Indonesia, upaya konstruksi geopolitik melalui upaya mengembangkan konsep "Indo-Pasifik" tidak bisa dilepaskan dari faktor benturan kepentingan great power seperti AS dan Tiongkok untuk mengamankan kepentingannya. Oleh karenanya Indonesia memiliki kepentingan untuk membentuk suatu arsitektur regional baru dengan memasukkan beberapa kekuatan lain seperti Jepang, India, Selandia Baru, Korea Selatan, dan Australia untuk memainkan peranan yang lebih di kawasan dan menyeimbangkan kekuatan di kawasan (Iriawan, 2017). Dengan masuknya negara-negara middle power seperti India, menjadikan multipolaritas semakin berkembang di kawasan. Ini penting untuk menjamin tidak ada negara dengan kekuatan besar terlalu mendominasi arah dari pembentukan kawasan Indo-Pasifik.

Konstruksi geopolitik Indonesia tersebut menurut Konstruktivisme, tidak dapat dilepaskan dari identitas nasional Indonesia. Identitas penting karena menyiratkan serangkaian kepentingan atau preferensi tertentu sehubungan dengan pilihan tindakan, dalam hal ini adalah kebijakan luar negeri. Sebuah negara akan mencoba melakukan hal yang benar sesuai dengan identitasnya, hal ini juga terjadi dalam kebijakan Indonesia untuk turut serta mengembangkan konsep Indo-Pasifik. Kerangka kerja ini terdiri dari tiga komponen, yaitu: nilai, preferensi, dan tindakan kebijakan luar negeri. Nilai menentukan preferensi arah kebijakan tertentu yang ingin dicapai, preferensi kebijakan ini pada gilirannya memerlukan tindakan tertentu yang terimplementasi dalam bentuk kebijakan luar negeri. Dalam praktiknya, sejumlah nilai yang berbeda sering ada, terkadang mengarah ke preferensi yang tidak sesuai dengan identitas suatu negara.

Masih dalam kacamata Konstruktivis, Pembukaan Undang-Undang Dasar Negara Republik Indonesia alinea ke 4 menjadi dasar identitas bagi Indonesia untuk ikut serta membangun sebuah arsitektur regional baru Indo-Pasifik yang berorientasi pada kerjasama dengan meminimalkan potensi konflik kepentingan antar negara. Ini sejalan dengan amanat UUD “....ikut melaksanakan ketertiban dunia yang berdasarkan kemerdekaan, perdamaian abadi, dan keadilan sosial...." (Jaringan Dokumentasi dan Informasi Hukum, 2018). Oleh karenanya, berlandaskan pada identitas nasional Indonesia tersebut, perlu ada suatu upaya untuk ikut serta menentukan arah kawasan baru tersebut, yang berbeda karakteristik dengan apa yang dipromosikan oleh negara-negara besar seperti Amerika Serikat. Oleh karenanya dalam berbagai kesempatan dalam berbagai forum multilateral Indonesia menyatakan bahwa Indonesia mendorong kawasan Indo-Pasifik sebagai kawasan yang transparan dan juga inklusif (Purwanto, 2018).

Indonesia sebagai sebuah negara yang secara geografis berada pada titik tengah antara Samudera Hindia dan juga Samudra Pasifik melihat sebuah celah untuk memainkan perananan yang lebih di dalam konsep kawasan baru ini. Konstruksi geopolitik Indonesia berkenaan dengan proses memobilisasi pengetahuan geografis, gagasan tentang politik dan dan identitas nasional 
menjadi pembangunan "visi geopolitik" Indonesia dalam kawasan Indo-Pasifik. Hal tersebut akan memiliki implikasi untuk kedua representasi identitas nasional dan hubungan internasional, sehingga kawasan Indo-Pasifik akan menyediakan geopolitik wawasan baru yang jauh dari nilainilai kontestasi antar negara kuat.

Melalui konstruksi geopolitik baru tersebut, Indonesia berusaha menghindari nilai-nilai khas pendekatan geopolitik tradisional yang memiliki kecenderungan untuk membagi dunia menjadi diskrit dan hierarkis, menjadi sebauh upaya subjektif yang bersandar pada nilai-nilai dan norma internasional. Tradisi geopolitik memerlukan serangkaian pengalaman yang beragam dan rumit yang dinegosiasikan dan disaring melalui banyak konteks yang berbeda, dan pengalaman Indonesia sebagai pemimpin dari ASEAN memungkinkan Indonesia untuk berberan aktif dalam kawasan baru ini.

Salah satu strategi nyata yang diambil oleh Indonesia adalah dengan membawa dan mempromosikan konsep Indo-Pasifik ke dalam berbagai forum multilateral melalui ASEAN. Dalam forum East Asia Summit ke-8 di Singapura, Menteri Luar Negeri Republik Indonesia Retno menjelaskan di hadapan 10 negara ASEAN dan 8 negara mitra ASEAN (Tiongkok, Jepang, Australia, Korea Selatan, India, Selandia Baru, Rusia, dan juga Amerika Serikat) bahwa Indonesia mendorong 3 poin dasar bagi Indo-Pasifik yang damai dan sejahtera melalui kerja sama maritim, konektifitas, dan pembangunan yang berkelanjutan (Kementerian Luar Negeri Republik Indonesia, 2018a). Sebelumnya, Indonesia telah menyampaikan konsep Indo-Pasifik ala Indonesia dalam berbagai kesempatan, namun dalam pertemuan EAS kali ini, wawasan IndoPasifik Indonesia tersebut disampaikan secara komprehensif dengan mengutamakan sentralitas ASEAN sehingga mendapatkan banyak dukungan dari negara-negara peserta EAS.

Upaya mengedepankan konsepsi Indo-Pasifik ala Indonesia ini untuk menghadapi perubahan geopolitik yang dihadapi Indonesia, khususnya pergeseran pertumbuhan ekonomi saat ini yang sejalan dengan transformasi lingkungan strategis di kawasan. Pada Konferensi Tingkat Tinggi (KTT) ke-32 ASEAN yang digelar di Singapura, Presiden Joko Widodo menekankan bahwa pengembangan kerangka kerja sama Indo-Pasifik harus berdasarkan prinsip-prinsip terbuka, inklusif, transparan dan mengedepankan kerja sama serta mengedepankan sentralitas ASEAN. Sentralitas ASEAN dikedepankan Indonesia agar ASEAN tetap relevan memainkan sentralitasnya dan menunjukkan kemampuan ASEAN dalam mengelola perubahan lingkungan strategis (Humas, 2018).

Untuk mewujudkan konsepsi Indo-Pasifik ini, Presiden Jokowi mengusulkan tiga upaya ASEAN ke depan. Pertama, ASEAN harus mampu menjadi motor bagi penciptaan enabling environment. Indonesia melalui ASEAN harus terus mengajak semua mitra untuk menghormati hukum dan norma internasional mengembangkan babit of dialogue, mengedepankan penyelesaian sengketa secara damai menghindari penggunaan kekerasan. Kedua, ASEAN harus dapat mendayagunakan berbagai modalitas untuk menanggulangi tantangan keamanan, termasuk kejahatan lintas negara (transnational crimes). Beberapa bentuk ancaman yang perlu mendapatkan perhatian antara lain adalah: radikalisme, terorisme, perdagangan narkoba, dan perompakan (piracy). Ketiga, ASEAN harus pro-aktif dalam menciptakan pusat pertumbuhan ekonomi baru, khususnya di Samudra Hindia. Oleh karena itu, Presiden melanjutkan, ASEAN harus terus menjaga sistem ekonomi yang terbuka dan adil. Ketiga upaya ini dapat dilakukan melalui 
beberapa bidang kerjasama seperti bidang maritim, konektivitas, dan pencapaian SDGs (Humas, 2018).

Konsep Indo-Pasifik yang digagas Indonesia merupakan platform ideal untuk kerja sama ekonomi. Hal tersebut dikarenakan Indo-Pasifik merupakan kawasan dengan pertumbuhan ekonomi paling dinamis di dunia (Kementerian Luar Negeri Republik Indonesia, 2018a). Berkaitan dengan konsep Indo-Pasifik, langkah awal dari upaya konstruksi geopolitik Indonesia di kawasan adalah melalui upaya Indonesia dan Selandia Baru menyusun EAS Leader's Statement on Combatting Marine Plastic Debris dan disahkan dalam KTT EAS bulan November 2018 (Kementerian Luar Negeri Republik Indonesia, 2018a). Indonesia melihat bahwa kondisi geopolitik di kawasan memunculkan tantangan bagi perdamaian, stabilitas, lingkungan, dan kemakmuran negara-negara di kawasan, sehingga kerja sama merupakan suatu keharusan bagi negara-negara di kawasan untuk mengatasi tantangan tersebut. Indonesia melihat, apabila IndoPasifik tidak dibangun berdasarkan landasan yang kuat, maka negara-negara di sepanjang Samudera Hindia dan Samudera Pasifik dinilai berpotensi menjadi objek tarik-menarik di antara kekuatan dunia.

Untuk itu, konstruksi geopolitik kawasan melalui pembangunan konsep Indo-Pasifik yang terbuka, transparan, inklusif, kooperatif, dan menghormati hukum internasional harus terus di dorong oleh Indonesia agar ASEAN dapat mempertahankan peran sentralnya. Hal itu karena ASEAN telah lama mengadopsi nilai-nilai tersebut, sehingga ASEAN berpotensi memainkan kepemimpinannya dalam kawasan baru ini. Sebagaimana pemahaman geopolitik dalam kacamata Konstruktivisme bahwa pemahaman kita tentang geopolitik dunia bergantung pada definisi yang kita gunakan untuk memahami dunia itu. Hal itu diakui oleh Tuathail bahwa konsep-konsep seperti geopolitik paling baik dipahami dalam konteks penggunaannya yang historis dan diskursif (Tuathail \& Agnew, 1992). Melalui pemahaman atas kajian geopolitik kritis yang berlandaskan Konstruktivisme, dapat terlihat secara eksplisit bahwa Indonesia sedang memasukkan ide-ide mereka pada konsep Indo-Pasifik melalui promosi konsep Indo-Pasifik ala Indonesia di berbagai forum multilateral karena menurut konstruktivisme, speech act yang dilakukan oleh Indonesia ini akan menghasilkan arsitektur geopolitik regional baru yang dipengaruhi oleh norma-norma dan konstruksi sosial.

Dalam Pernyataan Pers Tahunan Menteri Luar Negeri Republik Indonesia Tahun 2018 terangkum berbagai langkah strategis yang diambil oleh Indonesia untuk membentuk arsitektur regional di Indo-Pasifik (Kementerian Luar Negeri Republik Indonesia, 2018b). Pertama, mendorong kemitraan multilateralisme untuk menghormati hukum internasional (Partnership must be strengthened to prevent the mighty takes all). Kedua mempromosikan semangat co-opetition (cooperative competition), yakni semangat bekerja sama di tengah dunia yang penuh persaingan guna mencapai hasil optimum perlu terus didorong. Ketiga, memperluas ekosistem perdamaian, stabilitas, dan juga kesejahteraan, tidak hanya di ASEAN saja, namun juga di kawasan IndoPasifik. Ini dilakukan dengan menempatkan Indonesia dan ASEAN sebagai kunci dan pemain utama dalam menciptakan arsitektur regional Indo-Pasifik. Keempat, Indonesia membangun payung kerja sama Indo-Pasifik untuk memupuk rasa saling percaya (confidence building) dan kerja sama yang saling menguntungkan, serta menumbuhkembangkan babit of dialogue dalam arsitektur kerja sama di Indo-Pasifik. Dan yang terakhir, Indonesia ingin mengkonstruksi Indo-Pasifik melalui pendekatan building blocks, yakni: 
1. Secara bilateral dan pluri-lateral, mengintensifkan kerja sama di antara berbagai negara di Lingkar Indo-Pasifik dalam berbagai bidang strategis, khususnya keamanan, maritim, perdagangan dan investasi

2. Di tingkat kawasan, mendorong penguatan kerja sama IORA, sesuai Jakarta Concord dan Plan of Action 2017 - 2021, untuk menciptakan pusat-pusat pertumbuhan baru yang mendukung ekosistem perdamaian, stabilitas dan kemakmuran di Samudra Hindia

3. Menciptakan hubungan (linkage) berbagai kerja sama bilateral, plurilateral serta arsitektur kerja sama di Samudra Hindia dengan ASEAN-led mechanisms

Semua upaya yang dilakukan Indonesia dalam rangka mengedepankan ASEAN dalam konstruksi geopolitik Indo-Pasifik didasari oleh nilai penting ASEAN bagi kebijakan luar negeri Indonesia. Selain itu konstruksi Indo-Pasifik dapat menjadi jalan bagi Indonesia untuk memperbaiki kekurangan ASEAN selama ini khususnya terkait sikap ASEAN yang terpecah menghadapi Tiongkok. Melalui konstruksi konsepsi Indo-Pasifik, Indonesia dapat menyatukan ASEAN dan menghimpun kekuatan regional lainnya untuk menghadapi tantangan global, tidak terkecuali bangkitnya tiongkok dan sikap agresifnya di kawasan serta kemungkinan proteksionisme di kawasan Indo-Pasifik.

\section{Kesimpulan}

Dalam pandangan beberapa pihak, upaya Indonesia dalam ikut mengkonstruksi geopolitik kawasan melalui penegasan konsep Indo-Pasifik ala mereka telah di apresiasi. Beberapa negara misalnya telah mengidentifikasi Indonesia dan ASEAN, sebagai pendorong utama konsep Indo-Pasifik. Terlihat dari hasil KTT EAS di mana negara-negara yang hadir bersepakat dengan Indonesia untuk ikut serta mendorong terciptanya kawasan Indo-Pasifik yang kooperatif, inklusif, terbuka, transparan, dan menghormati hukum internasional. Oleh karena itu, melalui pengembangan konsep Indo-Pasifik tersebut, Indonesia sedang membentuk hubungan geopolitik yang tangguh di kawasan dengan berpijak pada akar identias nasionalnya. Sehingga kawasan baru ini nanti tidak berjalan dengan asas kontestasi, namun lebih ke arah kerjasama. Lebih jauh, Indonesia melalui ASEAN mendorong agar Indo-Pasifik memiliki sebuah payung kerja sama yang: bebas, terbuka, inklusif, komprehensif, dan bermanfaat bagi kepentingan jangka panjang semua negara di kawasan, serta dilandasi oleh komitmen bersama negara-negara di kawasan Indo-Pasifik terhadap perdamaian, stabilitas dan kemakmuran bersama. Ini tentunya sejalan juga dengan kepentingan nasional Indonesia untuk mewujudkan visi sebagai negara poros maritim dunia.

\section{Referensi}

Agastia, I. G. B. D., \& Perwita, A. A. B. (2016). Indonesia's Maritime Axis and the Security of Sea Lanes of Communications (SLOCs) in the Indo-Pacific. Jurnal Hubungan Internasional, 5(1), 10-21. Retrieved from https://journal.umy.ac.id/index.php/jhi/article/view/2247

Ayres, A. (2019). The U.S. Indo-Pacific Strategy Needs More Indian Ocean. Retrieved from https://www.cfr.org/expert-brief/us-indo-pacific-strategy-needs-more-indian-ocean Azwar, S. (2010). Metode Penelitian. Yogyakarta: Pustaka Pelajar. 
Bachmann, V., \& Sidaway, J. D. (2016). Brexit geopolitics. Geoforum, 77, 47-50. https://doi.org/https://doi.org/10.1016/j.geoforum.2016.10.001

Bakry, U. S. (2016). Metode Penelitian Hubungan Internasional. Yogyakarta: Pustaka Pelajar.

Chacko, P., \& Willis, D. (2018). No TitlePivoting to Indo-Pacific? The Limits of Indian and Indonesian Integration. East Asia, 35. Retrieved from https://link.springer.com/article/10.1007/s12140-018-9293-6

Chen, D. (2018). The Indo-Pacific Strategy: A Background Analysis. Retrieved from https://www.ispionline.it/it/pubblicazione/indo-pacific-strategy-background-analysis20714

Creswell, J. W. (2016). Research Design: Pendekatan Metode Kualitatif, Kuantitatif, dan Campuran. Yogyakarta: Pustaka Pelajar.

Damayanti, A. (2019). Indo-Pacific Maritime Cooperation: ASEAN Mechanisms on Security Towards Global Maritime Governance. Global \& Strategis, 13(1), 1-14. https://doi.org/http://dx.doi.org/10.20473/jgs.13.1.2019.1-44

Darmawan, A. B., \& Kuncoro, H. R. (8AD). Penggunaan ASEAN Way dalam Upaya Penyelesaian Sengketa Laut Tiongkok Selatan: Sebuah Catatan Keberhasilan? Andalas Journal of International Studies (AJIS), 1(2019), 43-61. https://doi.org/DOI: https://doi.org/10.25077/ajis.8.1.43-61.2019

De, P. (2019). Navigating the Indo-Pacific Cooperation. Retrieved from https://economictimes.indiatimes.com/blogs/et-commentary/navigating-the-indopacific-cooperation/

Glosserman, B. (2016). Can the United States Share Power in the Asia-Pacific. In Asia-Pacific Security: An Introduction (pp. 23-40). Washington DC: Georgetown University Press.

Hadiwinata, B. S. (2017). Studi dan Teori Hubungan Internasional: Arus Utama, Alternatif, dan Reflektivis. Jakarta: Yayasan Pustaka Obor Indonesia.

Hopf, T. (2012). The Promise of Constructivism in International Relations Theory. International Security, 23(1), 171-200. https://doi.org/https://doi.org/10.1162/isec.23.1.171

Humas. (2018). Presiden: Kerja Sama Indo-Pasifik Harus Inklusif dan Kedepankan Sentralitas ASEAN. Retrieved from https://setkab.go.id/presiden-kerja-sama-indo-pasifik-harusinklusif-dan-kedepankan-sentralitas-asean/

Iriawan, S. (2017). Dibalik Kemunculan Terminologi Indo-Pasifik. Retrieved from http://teritorial.com/opini/dibalik-kemunculan-terminologi-indo-pasifik/

Jaringan Dokumentasi dan Informasi Hukum. (2018). Undang-Undang Dasar 1945. Retrieved September 19, 2020, from http://jdih.pom.go.id/uud1945.pdf

Kementerian Luar Negeri Republik Indonesia. (2018a). Perkenalkan Konsep Indo-Pasifik, Indonesia Set the Tone di East Asia Summit. Retrieved from https://www.kemlu.go.id/id/berita/Pages/Perkenalkan-Konsep-Indo-Pasifik,Indonesia-Set-the-Tone-di-East-Asia-Summit-.aspx.

Kementerian Luar Negeri Republik Indonesia. (2018b). Pernyataan Pers Tabunan Menteri Luar Negeri Republik Indonesia. Jakarta: Kementerian Luar Negeri Republik Indonesia.

Khurana, Gurpreet S. (2007). Security of Sea Lines: Prospects for India-Japan Cooperation. Strategic Analysis, $\quad 31(1)$, 139-153. https://doi.org/https://doi.org/10.1080/09700160701355485 
Khurana, Gurpreet Singh. (2017). The Indo-Pacific Concept: Retrospect and Prospect. Retrieved from http:/ / cimsec.org/indo-pacific-concept-retrospect-prospect/34710

Limaye, S. P. (2014). India and ASEAN: Responses, Articles. Foreign Policy Research Centre Journal, (1). Retrieved from https://www.fprc.in/fprc_journal.php

Natalegawa, M. (2013). An Indonesian perspective on the Indo-Pacific'. Retrieved from https://www.thejakartapost.com/news/2013/05/20/an-indonesian-perspective-indopacific.html

Parker, G. (1998). Geopolitics: Past, Present and Future. United Kingdom: Pinter Pub Ltd.

Passarelli, D. M. (2014). Sea Change: Evolving Maritime Geopolitics in the Indo-Pacific Region. Washington DC: Stimson Center.

Purwanto, H. (2018). Indonesia continues to promote Indo-Pacific concept. Retrieved from https://en.antaranews.com/news/115020/indonesia-continues-to-promote-indopacific-concept.

Saeed, M. (2017). From the Asia-Pacific to the Indo-Pacific: Expanding Sino-U.S. Strategic Competition. China Quarterly of International Strategic Studies, 3(4), 499-512. https://doi.org/https://doi.org/10.1142/S2377740017500324

Situmeang, Y. K. N., \& Fadra. (2018). The North Natuna Sea Renamed as Geopolitics of Indonesia in Natuna. Scientific Research Journal, 6(1), 70-75. Retrieved from http://www.scirj.org/jan-2018-paper.php?rp=P0118489

Tertia, J., \& Perwita, A. A. B. (2018). Maritim Security in Indo-Pacific: Issues, Cha;;enges, and Prospects. Jurnal Ilmiah Hubungan Internasional, 14(1), 77-95. https://doi.org/https://doi.org/10.26593/jihi.v14i1.2795.77-95

Tuathail, G. O., \& Agnew, J. (1992). Geopolitics and discourse: Practical geopolitical reasoning in American foreign policy. Political Geography, 11(2), 190-204. https://doi.org/https://doi.org/10.1016/0962-6298(92)90048-X

Vihma, A. (2018). Special Section: Geoeconomics and Critical Geopolitics Geoeconomic Analysis and the Limits of Critical Geopolitics: A New Engagement with Edward Luttwak Antto Vihma. Geopolitics, 23(1), 1-21. https://doi.org/https://doi.org/10.1080/14650045.2017.1302928

Wagle, A. A. (2018). How will ASEAN balance a tug of power between China and US-led 'Quad' in the Indo-Pacific? Retrieved from https://theconversation.com/how-willasean-balance-a-tug-of-power-between-china-and-us-led-quad-in-the-indo-pacific101468

Wendt, A. (1992). No TitleAnarchy is what states make of it: the social construction of power politics. International Organization, 46(2), 391-425. https://doi.org/https://doi.org/10.1017/S0020818300027764

Woon, C. Y. (2018). China's Contingencies: Critical Geopolitics, Chinese Exceptionalism and the Uses of History. Geopolitics, 23(1), 67-95. https://doi.org/https://doi.org/10.1080/14650045.2017.1302429 